NASA/TM-2000-210514

\title{
Power and On-Board Propulsion System Benefit Studies at NASA GRC
}

David J. Hoffman

Glenn Research Center, Cleveland, Ohio 
Since its founding, NASA has been dedicated to the advancement of aeronautics and space science. The NASA Scientific and Technical Information (STI) Program Office plays a key part in helping NASA maintain this important role.

The NASA STI Program Office is operated by Langley Research Center, the Lead Center for NASA's scientific and technical information. The NASA STI Program Office provides access to the NASA STI Database, the largest collection of aeronautical and space science STI in the world. The Program Office is also NASA's institutional mechanism for disseminating the results of its research and development activities. These results are published by NASA in the NASA STI Report Series, which includes the following report types:

- TECHNICAL PUBLICATION. Reports of completed research or a major significant phase of research that present the results of NASA programs and include extensive data or theoretical analysis. Includes compilations of significant scientific and technical data and information deemed to be of continuing reference value. NASA's counterpart of peerreviewed formal professional papers but has less stringent limitations on manuscript length and extent of graphic presentations.

- TECHNICAL MEMORANDUM. Scientific and technical findings that are preliminary or of specialized interest, e.g., quick release reports, working papers, and bibliographies that contain minimal annotation. Does not contain extensive analysis.

- CONTRACTOR REPORT. Scientific and technical findings by NASA-sponsored contractors and grantees.
- CONFERENCE PUBLICATION. Collected papers from scientific and technical conferences, symposia, seminars, or other meetings sponsored or cosponsored by NASA.

- SPECIAL PUBLICATION. Scientific, technical, or historical information from NASA programs, projects, and missions, often concerned with subjects having substantial public interest.

- TECHNICAL TRANSLATION. Englishlanguage translations of foreign scientific and technical material pertinent to NASA's mission.

Specialized services that complement the STI Program Office's diverse offerings include creating custom thesauri, building customized data bases, organizing and publishing research results ... even providing videos.

For more information about the NASA STI Program Office, see the following:

- Access the NASA STI Program Home Page at $h t t p: / / w w w . s t i . n a s a . g o v$

- E-mail your question via the Internet to help@sti.nasa.gov

- Fax your question to the NASA Access Help Desk at 301-621-0134

- Telephone the NASA Access Help Desk at 301-621-0390

- Write to:

NASA Access Help Desk

NASA Center for AeroSpace Information 7121 Standard Drive

Hanover, MD 21076 
NASA/TM-2000-210514

\section{Power and On-Board Propulsion System Benefit Studies at NASA GRC}

David J. Hoffman

Glenn Research Center, Cleveland, Ohio

Prepared for the

Power Systems Conference

sponsored by the Society of Automotive Engineers

San Diego, California, October 31-November 2, 2000

National Aeronautics and

Space Administration

Glenn Research Center 


\section{Acknowledgments}

The author would like to acknowledge the current GRC System Assessment Team (SAT) members whose skills and efforts are greatly appreciated.

Available from

NASA Center for Aerospace Information 7121 Standard Drive

Hanover, MD 21076

Price Code: A03
National Technical Information Service 5285 Port Royal Road Springfield, VA 22100

Price Code: A03

Available electronically at http://gltrs.grc.nasa.gov/GLTRS 


\title{
Power and On-Board Propulsion System Benefit Studies at NASA GRC
}

\author{
David J. Hoffman \\ National Aeronautics and Space Administration \\ Glenn Research Center \\ Cleveland, Ohio 44135
}

\begin{abstract}
This paper discusses the value of systems studies that provide unbiased "honest broker" assessments of the quantified benefits afforded by advanced technologies for specific missions. The organization, format and approach used by the NASA Glenn Research Center (GRC) Systems Assessment Team (SAT) to perform system studies for the GRC advanced power and on-board propulsion technology development program is described. Three levels of assessments and a sensitivity analysis are explained and example results are presented. The impact of system studies results and some of the main challenges associated with systems studies are identified. A call for collaboration is made where system studies of all types from all organizations can be reviewed, providing a forum for the widest peer review to ensure accurate and unbiased technical content, and to avoid needless duplication.
\end{abstract}

\section{INTRODUCTION}

System studies provide the basis for sound technology program planning. The results of the tradeoff studies and technical assessments performed in system studies help provide the rationale to advocate and defend technology development. In its broadest application, system studies indicate the range of applicability of various technologies. More specifically, a system study can indicate the most beneficial technology for a given mission or application.

In the past, a successful case for a competing technology could be made by simply stating that it would cost less, weigh less or be more reliable than the baseline (or faster, better, cheaper, if you will). Now, in order to better justify the expense, technology program planners and financiers demand to know the magnitude of the technological benefit for specific missions or applications.

In many cases, the results of a system study do not indicate a clear choice of technology for a mission or application. One technology may result in the lowest mass yet have the highest development or non-recurring cost. Also, systems studies performed by different groups can lead to apparently contradictory results because the groups make slightly different assumptions for a number of parameters for different reasons, or use different criteria to assess the results. Assessment results can be further skewed if they are based on over optimistic predictions of the performance of newer, less mature technologies. Frequently, and for a variety of reasons, the actual performance of a newer technology in a specific application is much more conservative than initial optimistic expectations.

In short, a well-planned and defendable technology development program needs accurate, consistent, unbiased "honest broker" technology assessments that temper the enthusiasm of advocates and fairly quantifies the technology benefits for specific missions and applications. It is also desirable to eliminate duplication and repetition in performing the systems studies in order make the best use of human resources.

\section{GRC SYSTEM ASSESSMENT TEAM}

At the NASA Glenn Research Center, the System Assessment Team (SAT) has been formed to coordinate the performance of systems studies for the space power and on-board propulsion technology development programs. The SAT is intended to be a forum to coordinate internal peer review of technology trade studies, system assessments, and preliminary mission conceptual design and system sizing.

\section{ORGANIZATION}

Systems analysts from project, technology and cost organizations at GRC comprise the SAT. Team membership is open, with participants joining the group as necessary - i.e. when their work involves some sort of technology assessment or trade study that warrants wider coordination and review.

The core members of the SAT are matched up with task managers from the current GRC power and on-board propulsion technology development program. While the 
technology task managers are experts in their specific technology, they may not always be aware of the entire mission set or range of applications that their technology can benefit. Also, they may not have the analytical tools to quantify the mission or application benefit. The SAT systems analysts work closely with the technology task managers to ensure that the entire range of applicability of a given technology is identified, the features and benefits of the technology are documented, and the quantification of the technology benefits for specific missions and applications is performed. Currently, the SAT has analysts for each of the following specific technology areas:

- Photovoltaics - high efficiency solar cells, thin-film cells and advanced photovoltaic concepts such as quantum dot cells.

- Fuel Cells - active and passive regenerative fuel cells; "unitized" stacks.

- Chemical Batteries - Nickel-Hydrogen, Nickel Metal Hydride, Lithium Ion.

- Aerospace Flywheels - advanced concepts for energy storage and combined energy storage and spacecraft attitude control.

- Stirling Radioisotope Power System - free-piston Stirling thermal-to-electric energy conversion.

- Advanced Power Conditioning. Management \& Control Components - high efficiency converters with digital control; low and high temperature operation; power electronic building blocks.

- Low Temperature Electronics

- Advanced Electrochemical Capacitors - high specific power for peak power applications.

- Power System Surface Coatings \& Materials atomic oxygen resistant solar array coatings; intercalated graphite EMI shielding; thermal control surfaces and coatings.

- Power System Environmental Design Codes models for spacecraft charging, grounding and solar array arc mitigation.

Although the benefit of a specific power subsystem technology - power generation, energy storage and power management and distribution, or PMAD - can be quantified on its own, a more complete systems level assessment will indicate the full magnitude of the technology benefit for a given mission. Therefore, another SAT analyst assesses the mission benefit of the combination of advanced power generation, energy storage, and power management and distribution technologies. Even more, the synergistic benefits of advanced power and on-board electrical propulsion technologies warrant specific consideration. This analyst's approach also includes sensitivity studies to determine which parameters have the largest impact on the full system.

NASA/TM-2000-210514

\section{FORMAT}

The SAT meets weekly or bi-weekly to discuss normal business - discuss current events, monitor team member's progress on various studies, and plan future activities. Occasionally, there will be a focused peer review of an analysts' system study results, usually prior to an external briefing. Periodically, special seminars are held with technologists in order to review the latest technology developments and obtain updated values for some of the key technology performance parameters that drive the quantitative analysis. Quarterly briefings are held with the GRC power and on-board propulsion program managers to provide them the systems studies results they need to guide their program planning. The program managers also provide feedback on the types of analyses they would like to see performed.

\section{APPROACH}

An assessment performed in a system study can take a variety of forms and be performed at a number of levels. Most assessments take the form of a trade study where some aspect, typically mass, of alternative subsystem technologies are calculated and compared for a specific mission or application. The mission requirements must first be known or assumed so that the subsystems can be sized. Depending on the need for more or less detail and the time spent on the study, system sizing or performance models of varying levels of complexity are used. The following subsections discuss and illustrate some of the more common types of assessments.

\section{Top-Level Assessments}

Top-level assessments are used for rapid turnaround of very preliminary studies where only general trends are important. They are also used for "what if" assessments where a given level of performance is simply assumed so that the corresponding benefits can be quickly quantified. It then remains for the analyst or program manager to explain how this level of performance will be obtained.

An example of a top-level preliminary assessment showing the potential mission benefits of advanced power and on-board electrical propulsion can be found in [1]. This assessment is top-level in that it uses a model that operates with assumptions for the top-level performance parameters for each power subsystem (specific power, $W / \mathrm{kg}$ for solar arrays and specific energy, $W H / k g$ for energy storage, etc.). It also does not determine whether or not the advanced power and propulsion systems could have been actually implemented on the spacecraft studied, or that the benefits would have been actually realized (i.e. would the spacecraft actually flown more payload instruments?). However, the model does account for all major elements of the power and electric propulsion subsystems. Further, it was sophisticated enough to account for the 
fact that if more mass was allocated to the payload, the increased payload would require more power. The model used a feedback loop to iterate on the final spacecraft mass breakdown.

A unique feature of this analysis is that, for a variety of NASA missions, it demonstrates a truly synergistic effect - the spacecraft mass benefit of using electric propulsion together with advanced power is much greater than the mass benefit using advanced technology in any portion of the power and propulsion subsystems alone.

Figure 1 illustrates such results for the low Earth orbit Tropical Rainfall Measurement Mission (TRMM) spacecraft. The chart shows a $31 \%$ increase in the mass of the "balance-of-spacecraft" is possible if highefficiency solar arrays and flywheel energy storage is used in conjunction with low power Hall effect electric propulsion. The benefit of using these advanced power or propulsion technologies alone is a $20 \%$ increase in the balance-of-spacecraft mass. The balance-of-spacecraft includes the payload and subsystems other than power and propulsion.

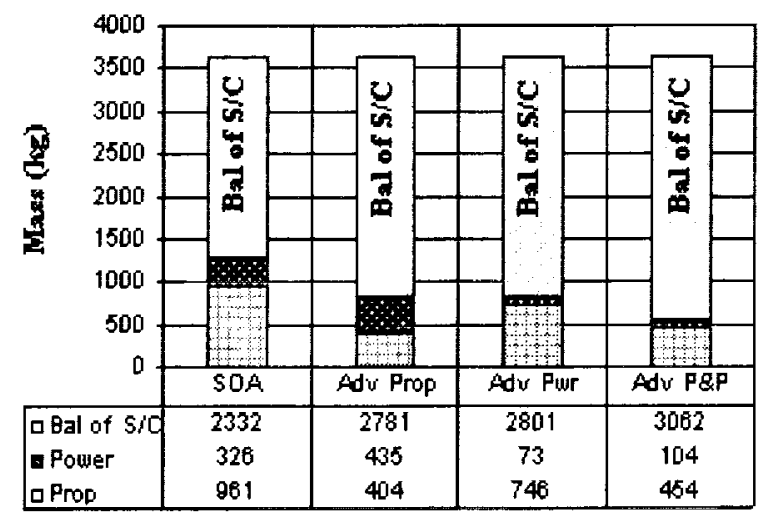

Figure 1 - Top-level model results showing the synergistic benefit of advanced power and electric propulsion for the TRMM spacecraft.

\section{Detailed Preliminary Assessments}

Given more time and the need for a more thorough study, detailed system assessments can be performed. In these cases, models using lower level parameters and algorithms that account for more detailed operation of power and propulsion systems must be developed or adapted and applied to specific missions. This takes time and requires knowledge or assumptions of more of the requirements regarding the mission, spacecraft and environment as well as design features of the power and propulsion subsystems in order to feed the more detailed models. If the time is available to perform such a study, and the model adequately benchmarked, there should be a higher level of confidence that the quantified results and trends are meaningful and realizable. However, the assessment should still be considered preliminary in that only a full-blown detailed design study will determine the proper characteristics of an actual system.

An example of a preliminary, yet detailed assessment is given in [2]. In this study, detailed power and solar electric propulsion computer models were used to size power systems for a 1 megawatt class Human Mars Mission Solar Electric Propulsion (SEP) stage and a smaller $15 \mathrm{~kW}$ Europa Mapper spacecraft. For both missions, the size (deployed area and mass) of a number of photovoltaic solar array power generation concepts was calculated using a time-dependent power system performance model iteratively coupled with the time-dependent trajectory model. Detailed solar array performance was modeled throughout each mission. The results of the study were used to recommend baseline power system options for these future missions.

For the Mars mission analyzed in this study, figure 2 shows the power required (dashed line) by the electric propulsion power processing units (PPUs) and the performance of a solar array using thin-film amorphous silicon/germanium solar cells as a function of mission time. The detailed electrical power system performance model used in this study accounts for all significant orbital environment effects, including thermal, particulate radiation, meteoroid/orbital debris and plasma. Note the rapid degradation in solar array power as the SEP stage spirals through the proton belts during the first 200 days of the mission.

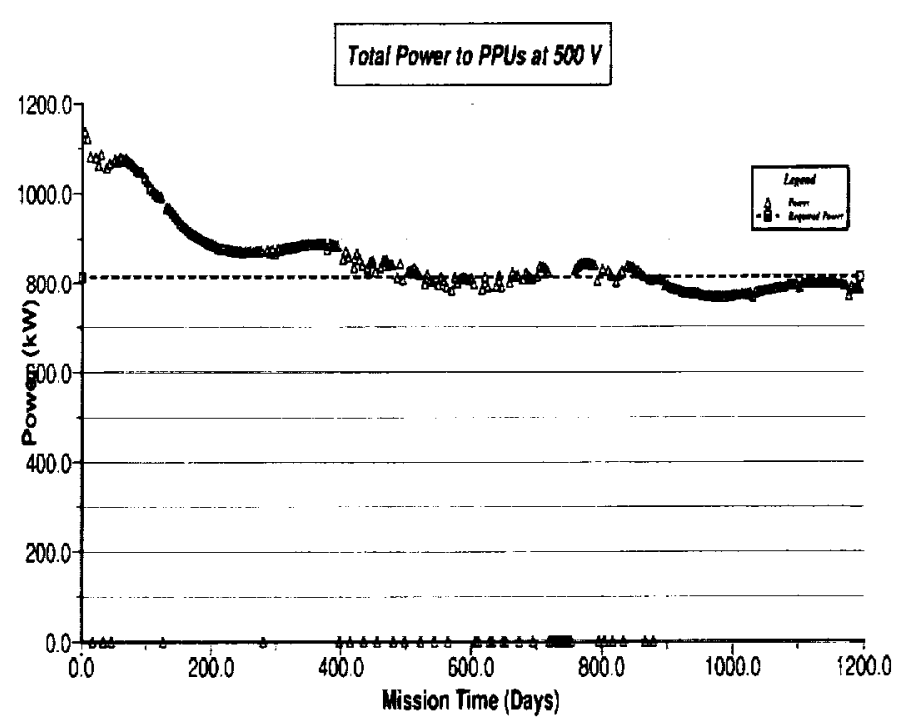

Figure 2 - Detailed power system performance modeling showing array performance over time.

\section{Intermediate-Level Assessments}

One step beyond top-level assessments, yet not as sophisticated as detailed assessments, are intermediate level, or first order assessments. These assessments use models that account for all significant phenomena and parameters that affect power and propulsion system 
performance, at least to a first order. They are similar to detailed assessments in that overall power system performance, say in terms of specific power $(w / \mathrm{kg})$, is a calculated value based on more detailed component models. They are similar to top-level assessments in that some parameters that effect power system sizing are best estimates for the mission under study, or linearly scaled from baseline system data. Intermediate-level assessments can be performed relatively quickly yet contain enough detail to better distinguish between closely competing technology options. They also can be used to perform rapid parametric analysis to discern trends among competing technology options.

An example of a first-order model and intermediate-level assessment is found in [3]. This reference describes a model developed to calculate size and estimate the relative cost of photovoltaic solar arrays for a variety of NASA missions. The model was applied in a parametric fashion to quantitatively determine the mass and cost trends among arrays using higher efficiency, yet heavier crystalline solar cell technology, versus arrays using less efficient, but much lighter thin-film solar cell technology deposited on lightweight flexible polyimide substrates.

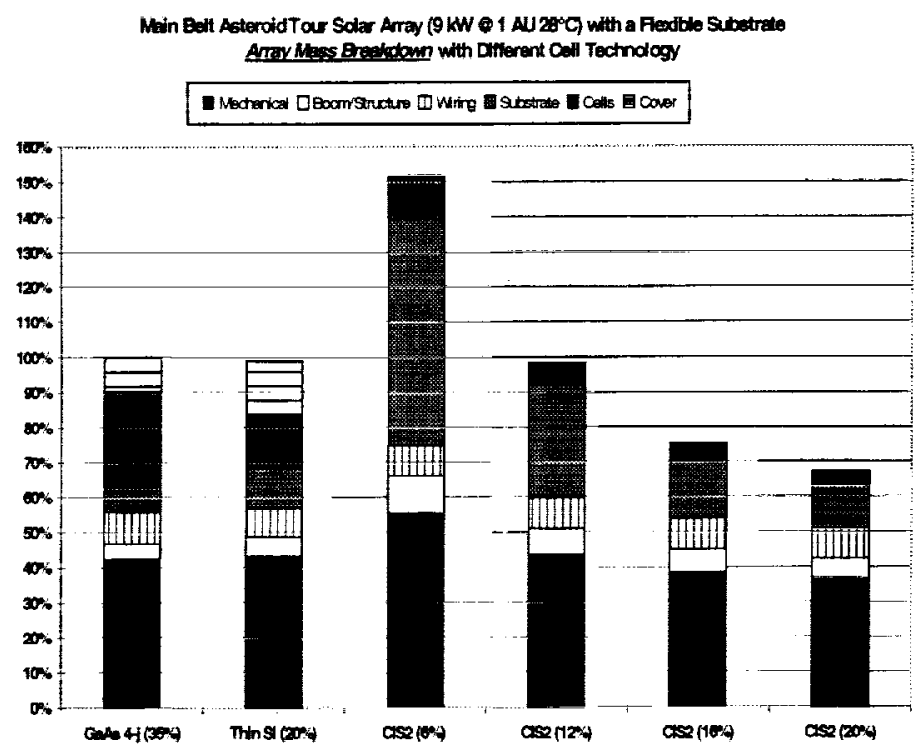

Figure 3 - Intermediate-level parametric analysis array mass predictions using a first-order array assessment model.

Figure 3 shows that for the given mission requirements, a solar array with $12 \%$ efficient lightweight thin-film solar cells (copper-indium-disulfide or CIS2) on a polyimide substrate will have the same mass as an array with either $20 \%$ efficient thin silicon crystalline cells (Thin Si) or $35 \%$ efficient four-junction gallium arsenide (GaAs $4-j$ ) based crystalline cells. While the goal of the thin-film cell technology developers is greater than $20 \%$ efficiency in order to mitigate solar array deployed area impacts, this system study indicated that thin-film cells with intermediate levels of efficiency $(\sim 12 \%)$ will be competitive from a mass standpoint.

\section{Sensitivity Analysis}

Although it could be considered a top-level or first-order intermediate assessment, a sensitivity analysis can be used to determine the relative importance of various component or subsystem parameters with respect to a key system or spacecraft-level parameter. In this case, the input parameters of a top-level or first order power or propulsion system model are varied, one at a time, while every other input parameter is held constant. The impact on system mass for each parameter variation is calculated. The most sensitive input parameter is the one that results in the largest percent change in the system mass per percent change in input parameter value.

For example, in a recent sensitivity analysis, the solar array specific power $(\mathrm{W} / \mathrm{kg})$, the energy storage specific energy $(\mathrm{WH} / \mathrm{kg})$ and the power management and distribution (PMAD) specific power (W/kg) input parameters in a top-level power system sizing model were varied from their nominal baseline values for a Low Earth Orbit (LEO) science mission.

Figure 4 shows the normalized results. For this LEO mission, the largest decrease in total power system mass occurs when the specific energy of the baseline chemical battery energy storage system improves. The model indicates that a factor of two improvement in specific energy will decrease the total mass of the power system by $18 \%$, everything else held constant.

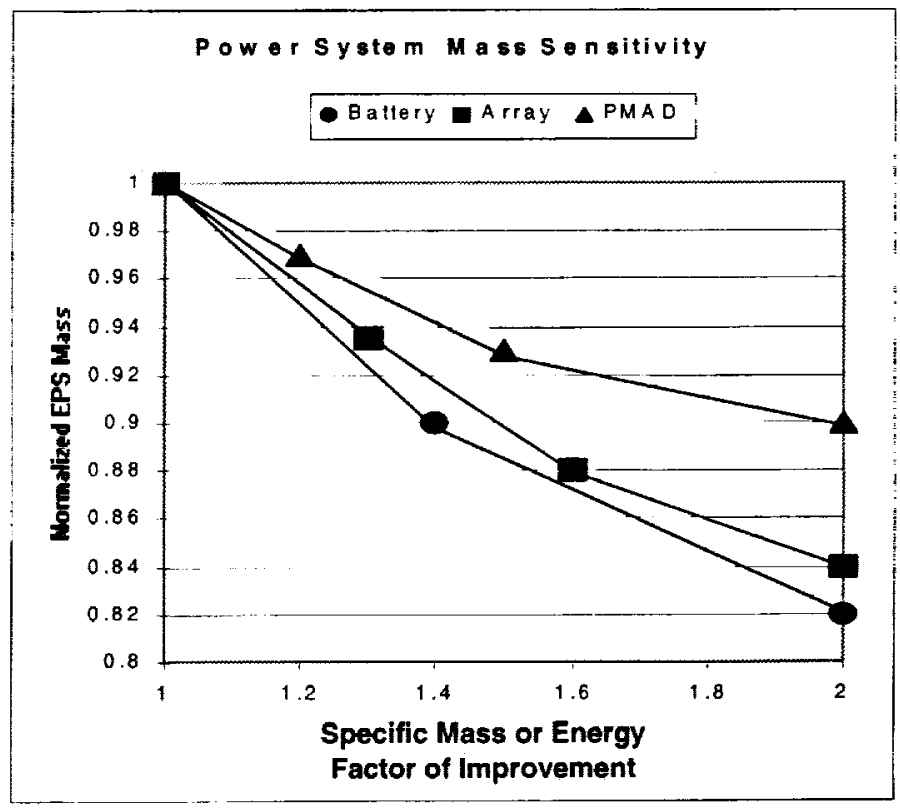

Figure 4 - The use of sensitivity analysis to determine the system-level impact of subsystem variations. 
There are a number of issues associated with this type of analysis, which are in part dependent on the level of sophistication of the underlying model. First of all, while a decent model will account for the interdependence of key parameters, some input parameters should not be varied independently. For example, significantly changing the value of specific energy for a chemical battery energy storage system implies switching to an alternative battery technology, which would in turn imply a different watthour ("roundtrip") efficiency. Simply varying the battery specific energy without changing the watt-hour efficiency may not be appropriate. To properly account for this, both parameters should be varied together.

Second, the results of a particular sensitivity analysis will only be applicable within a specific range of the nominal baseline mission values. Also, for power systems, the most sensitive parameter for a mission requiring significant amounts of energy storage may be completely different than the parameter for missions requiring no energy storage.

However, used carefully, the results from a thorough sensitivity analysis can be used to discern meaningful trends and set technology development priorities with respect to a given criterion (e.g. power system mass).

\section{IMPACT}

The results of systems studies from all levels of assessment can serve to identify the need for new technology development, identify a new application of an existing technology, further strengthen the case for an existing technology and/or application, indicate where additional systems studies should be performed, or flag where program re-planning should occur. The quantified benefits for specific missions provide defensible rationale for program advocacy and defense and can be included in proposals for new development.

\section{CHALLENGES}

Systems analysts strive to develop accurate models and perform quantitative assessments from which they can provide definitive recommendations to program and mission planners. However, if the analyst took the effort and care to estimate (quantitatively or qualitatively) and disclose the uncertainty associated with most preliminary assessments, the less definitive the trade study results and recommendations would become. In fact, trade studies performed by independent analysts from different organizations will often contain different results due to an accumulation in assumption differences, slightly different modeling techniques, and different weighting of the decision criteria. This does not necessarily mean that a given analyst is biased or that preliminary system study results are meaningless. It simply highlights the point that for preliminary top-level assessments, mission requirements and system performance are not well defined and there are a number of different ways to look at and evaluate a technology. Care must be taken to not decide "winning" and "losing" technologies on the basis of a preliminary study that looked at mass or cost alone. A more thorough, detailed assessment could determine whether or not the potential benefits are indeed realizable and help quantify other factors, such as system reliability or system integration and operation. The detailed study results could lead to much different conclusions than those derived from a preliminary assessment. Some other specific challenges are discussed below.

As just mentioned, more detailed mission and baseline system data is needed in order to better determine whether or not the preliminary benefits are actually realizable or to size an alternative system base on advanced technology. However, this detailed mission and system data is not always available or is not easily obtained by technology development organizations.

Also, a fair comparison of the performance of existing, mature technology with the projected performance of newer technologies is a significant challenge. Regarding the new technologies, there is not yet a database of actual performance from which to make projections. In these cases, the newer technologies almost always look favorable as compared with the mature technologies. One way to more fully characterize the potential performance of the newer technologies is through parametric analysis. In this approach, the performance of the newer technology is assumed through a range of more conservative (i.e. less optimistic) values than that that espoused by the advocates. In this way, the advantage of the newer technology can be assessed across a range of possibilities, including those that fall short of initial expectations.

Technology program planners sometimes seem to prefer quantified technology benefits for specific missions as opposed to benefits for representative missions or mission classes. The challenge then to an analyst evaluating a given technology is figure out how to quantify what benefit for how many missions of what type in order to provide sufficient rationale to justify technology development. The quantified mission benefits may be very meaningful to one mission planner, yet irrelevant to another. This requires the system analyst perform a large number of quantified mission benefit studies of different mission types to ensure relevancy to the largest number of mission planners.

Finally, most decisions boil down to one of cost. However, advanced development and non-recurring costs, let alone flight hardware recurring costs are very hard to estimate for immature technologies. One way to mitigate the uncertainty associated with the absolute cost of a technology is to perform relative costs estimates. In this case, if the absolute cost relationships are inaccurate, at least all options are costed using the same methods so that the relative costs may be reasonable. 


\section{COLLABORATION}

Peer-reviewed, unbiased assessments that fairly quantify the benefits of technologies for specific missions should be of interest to the technical community at large, as well as technology program and mission planners. Therefore, it would be beneficial to present system studies results from many different organizations. A special conference or other meeting would provide a useful venue for systems analysts to present to each other and to technology program planners and mission planners.

The peer review in this forum would expose parochialism and overt salesmanship, ensuring the most technically accurate and fair assessments get the greatest recognition. Widespread dissemination of results would also help avoid the needless duplication of studies.

\section{SUMMARY}

This paper discussed the value of systems studies that provide unbiased "honest broker" assessment of the quantified benefits afforded by advanced technologies. The organization, format and approach used by the NASA GRC Systems Assessment Team to perform system studies for the GRC advanced power and onboard propulsion technology development program were outlined. Three levels of assessments were explained (Top-Level, Intermediate, and Detailed) and example results were presented. Sensitivity analysis used to analytically determine the most sensitive subsystem parameter was described.

It was then stated that system study results can be used to identify the need for new technology development, identify a new application of an existing technology, further strengthen the case for an existing technology and/or application, indicate where additional systems studies should be performed, or flag where program replanning should occur.

Some of the main challenges associated with systems studies were identified and discussed, namely the uncertainty associated with the preliminary nature of the study, the lack of detailed mission and system information, the difficulty assessing the performance of mature versus new technology, the need to perform a large number of quantified mission benefit studies to ensure the widest relevancy, and the perennial problems associated with cost estimating.

Finally a call for collaboration was made where system studies of all types from all organizations are reviewed. Here, the goal is to provide a venue for widespread communication and dissemination of results, a forum for the widest technical community peer review to ensure accurate and unbiased technical content, and to avoid needless duplication.

\section{REFERENCES}

1. Mason, Lee S., Oleson, Steven R., "Spacecraft Impacts with Advanced Power and Electric Propulsion", NASATM2000-209912, 2000 Aerospace Conference, Big Sky, Montana, March 2000.

2. Kerslake, Thomas W., Gefert, Leon P., "Solar Power System Analyses for Electric Propulsion Missions", NASATM-1999-209289, $34^{\text {th }}$ Intersociety Energy Conversion Engineering Conference, Vancouver, British Columbia, Canada, August 1999.

3. Hoffman, David J., Kerslake, Thomas W., Jacobs, Mark K., Ponnusamy, Deva, "Thin-Film Photovoltaic Solar Array Assessment", $35^{\text {th }}$ Intersociety Energy Conversion Engineering Conference, Las Vegas, Nevada, July 2000.

\section{CONTACT}

Dave Hoffman works in the Power and Propulsion Office at the NASA Glenn Research Center in Cleveland, Ohio and can be reached via the following methods: Email: David.J.Hoffman@grc.nasa.gov; Phone: (216)433-2445; Fax: (216)433-2995. 


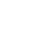

$=$ 
Public reporting burden for this colfection of information is estimated to average 1 hour per response, including the time for revlewing instructions, searching existing data sources, gathering and maintaining the data needed, and completing and reviewing the collection of information. Send comments regarding this burden estimate or any other aspect of this collection of intormation including suggestions for reducing this burden, to Washington Headquarters Services, Directorate tor Information Operations and Feports, 1215 JeHerson Davis Highway, Suite 1204, Arlington, VA 22202-4302, and to the Office of Management and Budget, Paperwork Reduction Project (0704-0188), Washington, DC 20503.
1. AGENCY USE ONLY (Leave blank)
2. REPORT DATE
October 2000
3. REPORT TYPE AND DATES COVERED
Technical Memorandum

4. TITLE AND SUBBTITLE

Power and On-Board Propulsion System Benefit Studies at NASA GRC 5. FUNDING NUMBERS

6. AUTHOR(S)

David J. Hoffman

7. PERFORMING ORGANIZATION NAME(S) AND ADDRESS(ES)

National Aeronautics and Space Administration

John H. Glenn Research Center at Lewis Field

Cleveland, Ohio 44135-3191

WU-632-6A-1K-00

9. SPONSORING/MONITORING AGENCY NAME(S) AND ADDRESS(ES)

10. SPONSORING/MONITORING

National Aeronautics and Space Administration

Washington, DC 20546-0001

8. PERFORMING ORGANIZATION

REPORT NUMBER

E-12482 AGENCY REPORT NUMBER

NASA TM-2000-210514

00PSC-57

11. SUPPLEMENTARY NOTES

Prepared for the Power Systems Conference sponsored by the Society of Automotive Engineers, San Diego, California, October 31-November 2, 2000. Responsible person, David J. Hoffman, organization code 6920, 216-433-2445.

12a. DISTRIBUTION/AVAILABILITY STATEMENT

12b. DISTRIBUTION CODE

Unclassified-Unlimited

Subject Categories: 18 and 20

Distribution: Nonstandard

Available electronically at http://gltrs.grc.nasa.gov/GLTRS

This publication is available from the NASA Center for AeroSpace Information, 301-621-0390.

13. ABSTRACT (Maximum 200 words)

This paper discusses the value of systems studies that provide unbiased "honest broker" assessments of the quantified benefits afforded by advanced technologies for specific missions. The organization, format and approach used by the NASA Glenn Research Center (GRC) Systems Assessment Team (SAT) to perform system studies for the GRC advanced power and on-board propulsion technology development program is described. Three levels of assessments and a sensitivity analysis are explained and example results are presented. The impact of system studies results and some of the main challenges associated with systems studies are identified. A call for collaboration is made where system studies of all types from all organizations can be reviewed, providing a forum for the widest peer review to ensure accurate and unbiased technical content, and to avoid needless duplication.

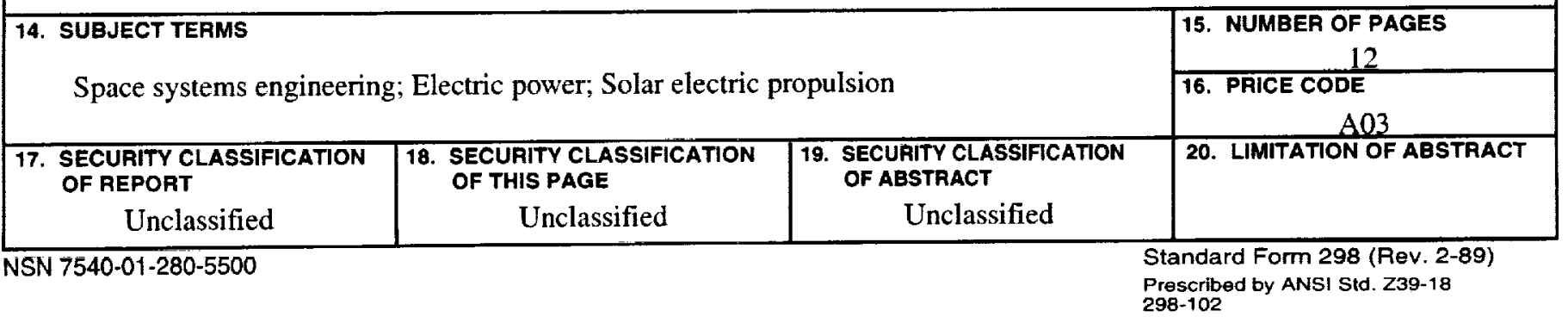

